\title{
The sensitivity of the array resistivity log to mud filtrate invasion and its primary five-parameter inversion for improved oil water recognition
}

\author{
Deng Shaogui ${ }^{1 *}$, Sun Qingtao ${ }^{1}$, Li Hu${ }^{1}$, Huo Ningning ${ }^{1}$ and He Xuquan ${ }^{2}$ \\ ${ }^{1}$ School of Geosciences, China University of Petroleum (East China), Shandong 266555, China \\ ${ }^{2}$ PetroChina Southwest Oil \& GasField Company, Sichuan 610051, China \\ (C) China University of Petroleum (Beijing) and Springer-Verlag Berlin Heidelberg 2012
}

\begin{abstract}
In order to improve reservoir fluid recognition, the sensitivity of array resistivity response to the difference of the invasion properties in both oil-bearing layers and water layers is analyzed. Then the primary inversion is carried out based on the array resistivity log. The mud invasion process is numerically simulated based on the oil-water flow equation and water convection diffusion equation. The results show that the radial resistivity of a fresh mud-invaded oil-bearing layer presents complex distribution characteristics, such as nonlinear increase, increasing to decreasing and low resistivity annulus, and the resistive invasion profile of a water layer is monotonic. Under specific conditions, array resistivity log can reflect these changes and the array induction log is more sensitive. Nevertheless, due to the effect of factors like large invasion depth, reservoir physical and oil-bearing properties, the measured apparent resistivity may differ greatly from the actual mud filtrate invasion profile in an oil-bearing layer. We proposed a five-parameter formation model to simulate the complex resistivity distribution of fresh mud-invaded formation. Then, based on the principle of non-linear least squares, the measured array resistivity log is used for inversion with the Marquardt method. It is demonstrated that the inverted resistivity is typically non-monotonic in oil-bearing layers and is monotonic in water layers. Processing of some field data shows that this is helpful in achieving efficient reservoir fluid recognition.
\end{abstract}

Key words: Oil-water recognition, mud filtrate invasion, array resistivity log, five-parameter inversion model

\section{Introduction}

Mud filtrate invasion in formations results in separation of apparent resistivities with different investigation depths, which thereby can be used to qualitatively identify the property of formation pore fluid. However, conventional shallow and deep dual laterolog/induction resistivity deviates greatly from the actual formation resistivity surrounding the well borehole (Deng et al, 2010). Utilizing electric logging data for formation parameter inversion is an important technology (Yang and $\mathrm{Wu}, 2005$ ), but the existing threeparameter/four-parameter inversion model does not get close to the complex resistivity distribution in the formation when mud filtrate invasion happens. Array logging is the developing trend of logging tools. Large companies such as Schlumberger and Atlas subsequently put their high resolution array laterolog tools (HRLA, HDLL) and array induction log tools (AIT, HDIL) to market, and these tools can provide 5-6 resistivity curves with different investigation

*Corresponding author. email: dengshg@upc.edu.cn Received January 11, 2012 depths (Griffiths et al, 1999; Chen et al, 1998; Barber and Rosthal, 1991; Smits et al, 1998; Wu et al, 2008; Yang and Nie, 2000; Strickland et al, 2003). They can be applied to reflecting mud filtrate invasion properties, and also provide a powerful method for reservoir fluid recognition (Chew and Liu, 1994; Gao et al, 2007). Taking fresh mud invasion as an example, we studied the formation resistivity distribution characteristics and the corresponding array resistivity logging response, and further analyzed the sensitivity of the array resistivity log to the difference between oil-bearing layers and water layers when mud filtrate invasion happens. Then a fiveparameter formation model is constructed in order to achieve better application in reservoir fluid recognition using an array resistivity log.

\section{Numerical simulation of mud filtrate invasion in reservoirs}

\subsection{Two-phase flow equation in reservoirs with mud filtrate invasion}

Assume that mud filtrate and formation fluid in the 
displacement process is not miscible, and the reservoir rock and fluid are both slightly compressible. Fluid percolation complies with Darcy's law. Then according to the B-L water displacing oil theory, the water-oil flow equation can be depicted as follows (Liu and Zhang, 2005; Dewan and Chenvert, 1993):

$$
\begin{aligned}
& \nabla \cdot\left[\rho_{\mathrm{o}} \frac{k k_{\mathrm{ro}}\left(s_{\mathrm{o}}\right)}{\mu_{\mathrm{o}}} \nabla\left(p_{\mathrm{o}}-h \rho_{\mathrm{o}} g\right)\right]=\frac{\partial\left(\varphi \rho_{\mathrm{o}} s_{\mathrm{o}}\right)}{\partial t} \\
& \nabla \cdot\left[\rho_{\mathrm{w}} \frac{k k_{\mathrm{rw}}\left(s_{\mathrm{w}}\right)}{\mu_{\mathrm{w}}} \nabla\left(p_{\mathrm{w}}-h \rho_{\mathrm{w}} g\right)\right]=\frac{\partial\left(\varphi \rho_{\mathrm{w}} s_{\mathrm{w}}\right)}{\partial t}
\end{aligned}
$$

where, $p_{\mathrm{w}}$ and $p_{\mathrm{o}}$ are water phase pressure and oil phase pressure; $s_{\mathrm{o}}$ and $s_{\mathrm{w}}$ are oil and water saturations; $\mu_{\mathrm{o}}$ and $\mu_{\mathrm{w}}$ are oil and water viscosities; $k_{\mathrm{ro}}$ and $k_{\mathrm{rw}}$ are oil and water two phase relative permeabilities; $\varphi$ is formation porosity; $h$ is formation depth; $g$ is gravity acceleration; $\rho_{\mathrm{w}}$ and $\rho_{\mathrm{o}}$ are water and oil densities; $t$ is the invading time.

\subsection{Water convection diffusion equation during mud filtrate invasion}

The salinities of mud filtrate and formation water are usually different and they physically mix with each other in the process of mud filtrate invasion. Convection diffusion happens between ions, which can be depicted as:

$$
\nabla \cdot\left[\frac{k k_{\mathrm{rw}} c_{\mathrm{w}}}{\mu_{\mathrm{w}}} \nabla\left(p_{\mathrm{w}}-\rho_{\mathrm{w}} g h\right)\right]=\frac{\partial\left(s_{\mathrm{w}} c_{\mathrm{w}} \varphi\right)}{\partial t}
$$

where, $c_{\mathrm{w}}$ is the salinity of porosity water.

\subsection{Determination of formation radial resistivity}

For sandstone or shaly sandstone, the radial resistivity can be determined by

$$
R_{t}=\frac{a b R_{\mathrm{wz}}}{\varphi^{m} s_{\mathrm{w}}^{n}}
$$

where $R_{\mathrm{wz}}$ is the resistivity of porosity water, $a$ and $b$ are lithology factors, $m$ and $n$ are the porosity factor and saturation factor.

In order to implement numerical simulation, specific simulation conditions are assumed as follows. Mud filtrate salinity is $38 \mathrm{~g} / \mathrm{L}$ and formation water salinity is $78 \mathrm{~g} / \mathrm{L}$. The bounded water saturation is $20 \%$, residual oil saturation is $20 \%$, porosity is $10 \%$ and permeability is $50 \times 10^{-3} \mathrm{um}^{2}$. The oil saturations of the oil layer, the water-oil layer and the water layer are respectively $80 \%, 50 \%$ and $20 \%$. Formation temperature is $101{ }^{\circ} \mathrm{C}$, crude oil viscosity is $30 \mathrm{mPa} \cdot \mathrm{s}$, crude oil density is $0.85 \mathrm{~g} / \mathrm{cm}^{3}$, pore water viscosity is $5 \mathrm{mPa} \cdot \mathrm{s}$, pore water density is $1 \mathrm{~g} / \mathrm{cm}^{3}$, pressure difference between borehole and formation is $2 \mathrm{MPa}$, borehole diameter is $20 \mathrm{~cm}$, mud resistivity is $1 \Omega \cdot \mathrm{m}$. $a$ and $b$ in Eq. (4) are assumed to be 2.0304 and 1.086, and $m$ and $n$ are respectively 1.5372 and 1.5458 .

\subsection{Distribution characteristics of radial resistivity in reservoirs with mud filtrate invasion}

Fresh mud invasion results in complex non-linear variation of radial resistivity distribution, as shown in Fig. 1. The curves with different colors in the figure are various times of mud filtrate invasion in the range from 0.5 day to 40 days. Besides the difference of the resistivity value, the oil-bearing layer also shows non-linear conductive invasion characteristics, that is, a lower resistivity in the invasion zone than in the original formation, which is accompanied by an obvious "low resistivity annulus", as shown in Fig. 1(a). In the water layer, however, an obvious resistive invasion is exhibited, as shown in Fig. 1(b). While in the water-oilbearing layer, the resistivity distribution shows a non-linear rising and falling trend, also accompanied by a slight "low resistivity annulus". Besides, the resistivity in the flushed zone is higher than that in the original formation. The three cases reflect the resistivity distribution characteristics in reservoirs with fresh mud invasion, and they are mainly affected by the reservoir fluid properties. This is because the physical change of the rock matrix can only result in changes of invasion depth and the value of formation resistivity but has little effect on the resistivity distribution shape. In Fig. 1(d), the formation porosity is $20 \%$, permeability is $1000 \times 10^{-3} \mathrm{um}^{2}$ and all the other conditions are the same as in Fig. 1(b).
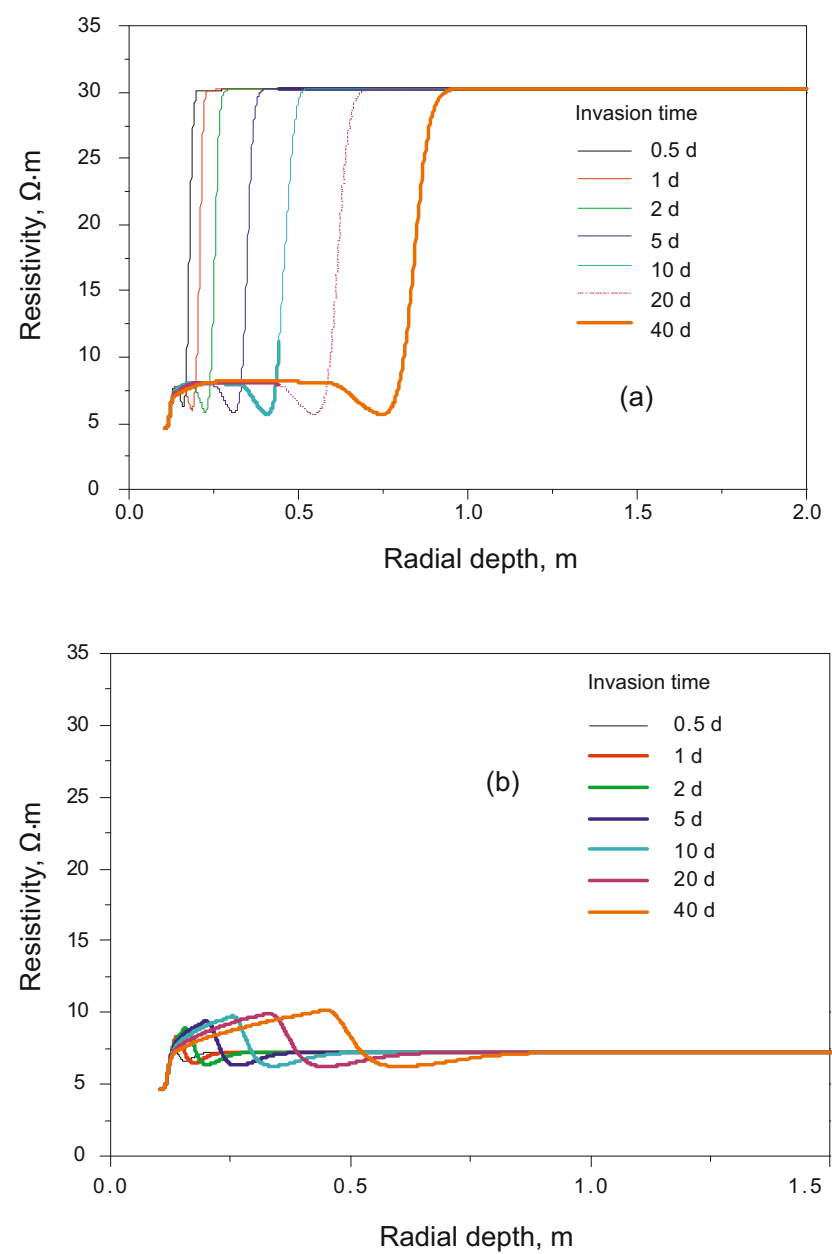

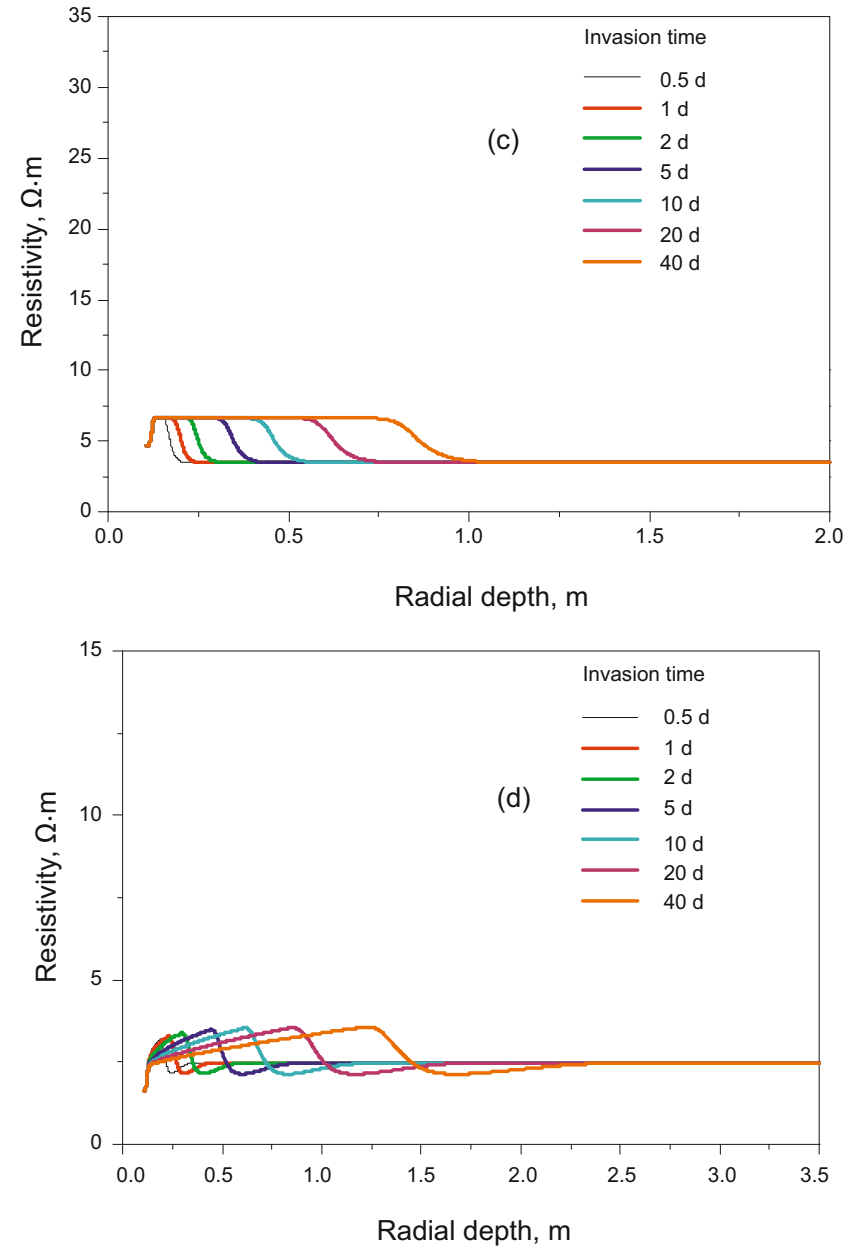

Fig. 1 Radial resistivity distribution in reservoirs with mud filtrate invasion

\subsection{Array resistivity logging response characteristics in reservoirs with fresh mud invasion}

We take the high resolution array laterolog tool from Schlumberger (HRLA) and the high resolution array induction $\log$ tool from Atlas (HDIL) for example. We analyze the logging response of the array resistivity $\log$ in the process of mud filtrate invasion. The array laterolog can provide six apparent resistivity values (RLA) with different investigation depths. RLA1, RLA2, RLA3, RLA4 and RLA5, with investigation depths of $0.23 \mathrm{~m}, 0.29 \mathrm{~m}, 0.37 \mathrm{~m}, 0.45 \mathrm{~m}$ and

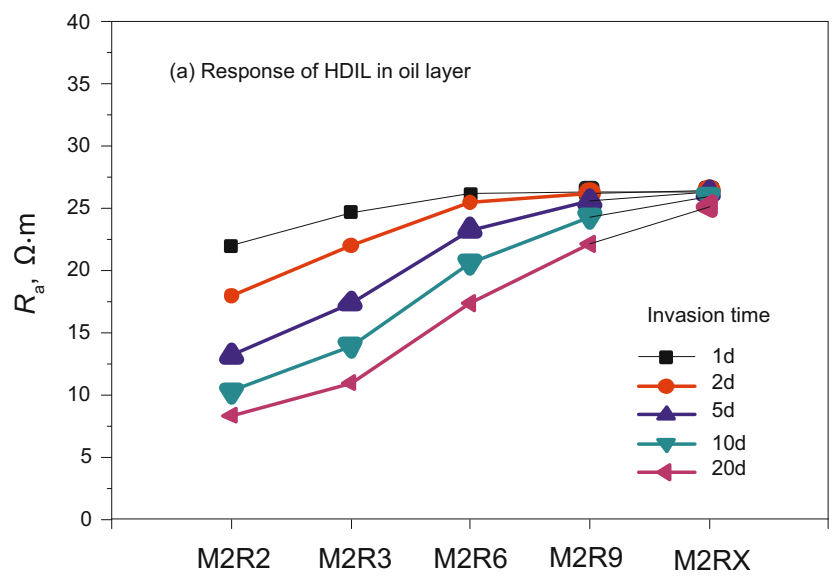

$0.70 \mathrm{~m}$, respectively, can be applied to reflecting the radial resistivity distribution in reservoirs with mud filtrate invasion. While RLA0, not the target in this paper, can be used to measure borehole mud resistivity. The investigation depth is defined as the investigation distance within which the medium contributes to $50 \%$ of the whole signal. The array induction log can provide resistivity curves with three longitudinal resolutions and six investigation depths. In this paper, only the resolution of $0.6 \mathrm{~m}$ is considered, and similarly, M2R2, M2R3, M2R6, M2R9 and M2RX are applied to analyzing mud filtrate invasion properties with investigation depths of $0.5 \mathrm{~m}, 0.75 \mathrm{~m}, 1.5 \mathrm{~m}, 2.25 \mathrm{~m}$ and $3.05 \mathrm{~m}$, respectively. M2R 1 with the shallowest investigation depth can be also used to measure borehole mud resistivity.

The simulation results show that in the oil-bearing layer, both the array induction $\log$ and the array laterolog exhibit a conductive invasion characteristic, that is, as the invasion time becomes longer, the apparent resistivity decreases, and the deep resistivity is bigger than the shallow resistivity, as shown in Figs. 2(a) and 2(b). In the water-oil-bearing layer, the change of array induction log is more obvious, as shown in Fig. 2(c). When the invasion time is short, the curves show an obvious positive difference and the shallow and deep resistivity forms an upper convex shape. As the invasion time becomes longer, the shallow and deep resistivity exhibits a "low resistivity annulus" characteristic. By contrast, the array laterolog always retains a resistive mud filtrate invasion characteristic, as shown in Fig. 2(d). Also from this figure, we can find that when the invasion time is short, the apparent resistivity decreases obviously, and with the invasion time getting longer, the resistivity increases. In water layer, both the array induction $\log$ and the array laterolog show a resistive mud filtrate invasion characteristic, as shown in Figs. 2(e) and 2(f). The array resistivity log responses are different when fresh mud invades reservoirs with different fluid properties, and the response also differs from the actual resistivity distribution when mud filtrate invasion happens. For instance, mud filtrate invasion in both the oil-bearing layer and wateroil-bearing layer can result in a low resistivity annulus, as shown in Figs. 1(a) and 1(b), but the array resistivity log can present this phenomenon only under specific conditions. Even the array laterolog only shows a resistive mud filtrate invasion characteristic in the water-oil-bearing layer.

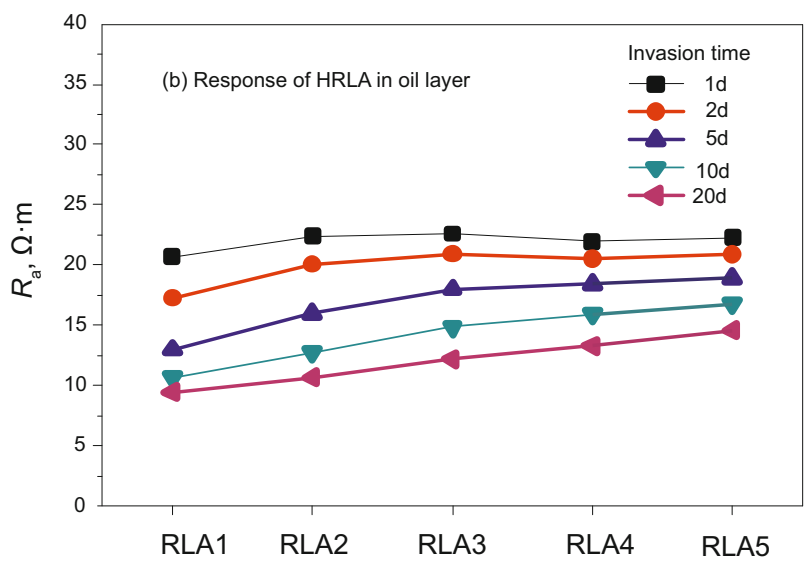



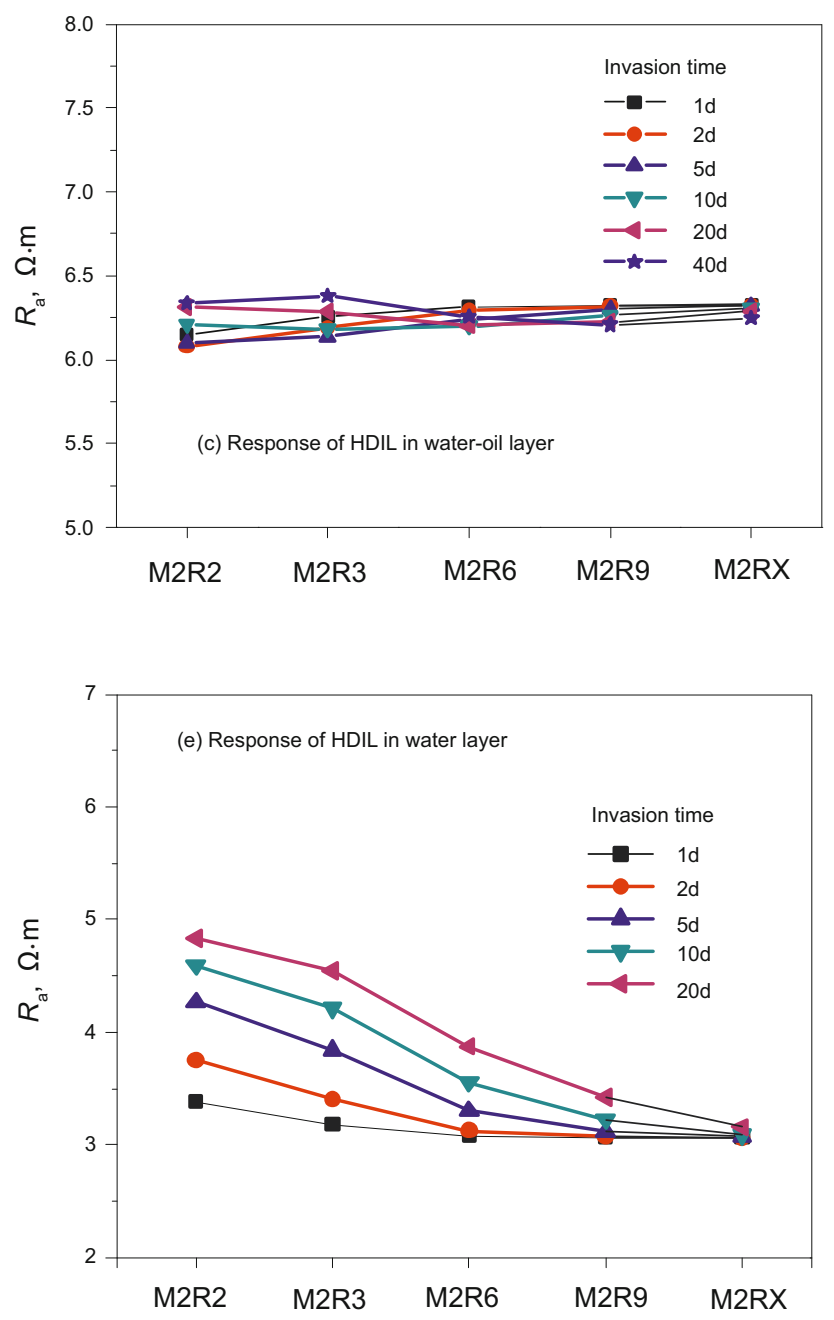
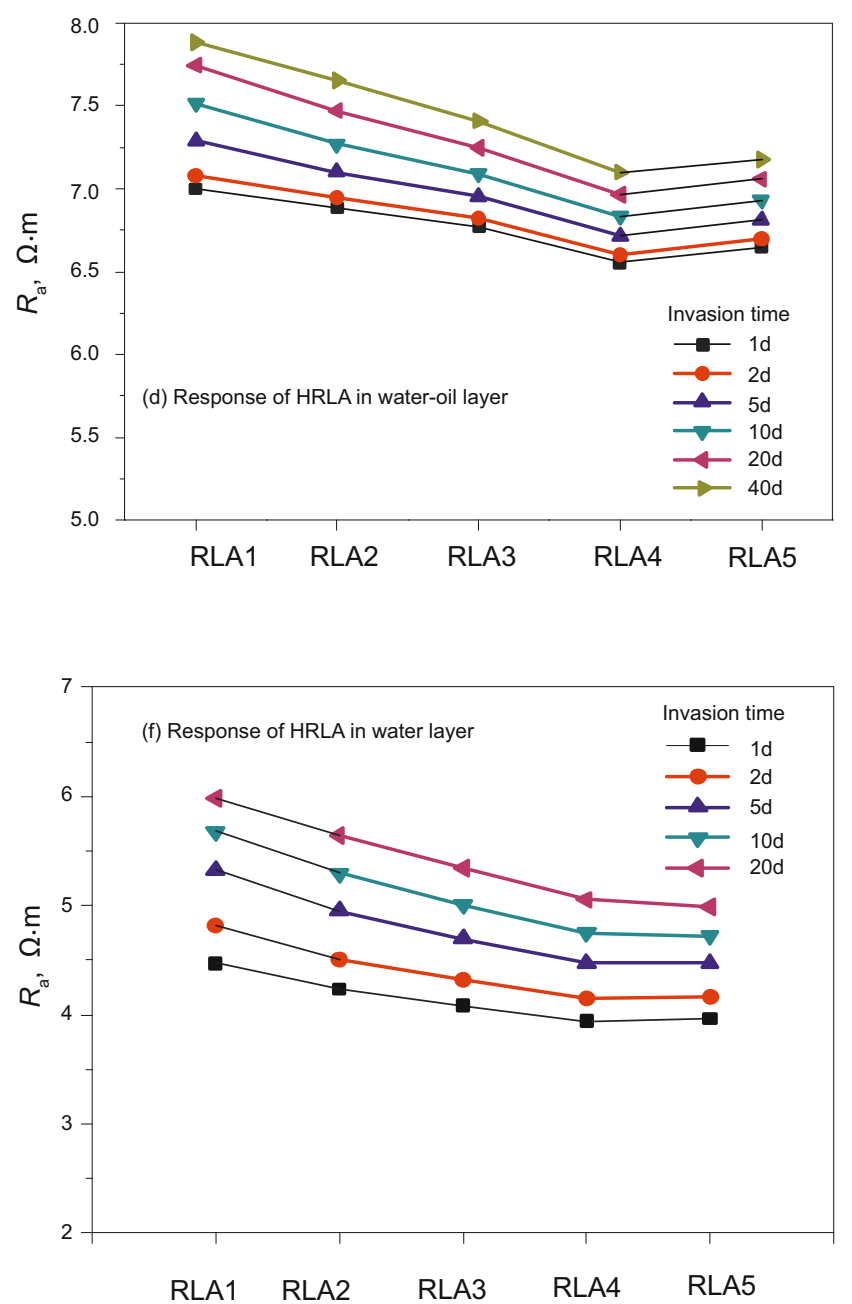

Fig. 2 Logging responses of the array induction $\log$ and array laterolog in the process of mud filtrate invasion

\section{Reservoir fluid recognition on the basis of mud filtrate invasion characteristics analysis}

The response of the array resistivity logging in reservoirs with mud filtrate invasion depends on the reservoir fluid properties, and the characteristics of conductive invasion. An upper convex and low resistivity annulus often indicates an oil-bearing reservoir. Fig. 3 shows the logging curves of well $\mathrm{X}$ in an oilfield in China, and two layers No.1 and No.2 are mainly analyzed. The array induction log of No.1 layer shows $\mathrm{M} 2 \mathrm{R} 2<\mathrm{M} 2 \mathrm{R} 3<\mathrm{M} 2 \mathrm{R} 6<\mathrm{M} 2 \mathrm{R} 9>\mathrm{M} 2 \mathrm{RX}$ while No.2 layer shows $\mathrm{M} 2 \mathrm{R} 2<\mathrm{M} 2 \mathrm{R} 3<\mathrm{M} 2 \mathrm{R} 6>\mathrm{M} 2 \mathrm{R} 9>\mathrm{M} 2 \mathrm{RX}$. The shallow and deep resistivity forms an upper convex shape for the two layers, indicating an oil-bearing reservoir characteristic. This is also consistent with the oil testing conclusions. Some scholars proposed to use the low resistivity annulus indication to recognize an oil-bearing layer and achieved good application (Li et al, 2005). However, due to the complex effects of invasion depth, reservoir physical properties, oil-bearing property, formation thickness and wall rock, the measured array resistivity often shows great variety and complexity, and the low resistivity annulus is only one characteristic of the complex logging responses in oil-bearing formations.

\section{Five-parameter inversion of the array resistivity log}

\subsection{Five-parameter formation model}

The slight difference in actual measured resistivity curves in oil-bearing and water layers and even the negative difference in oil-bearing layers result in difficulty in reservoir fluid recognition. However, the resistivity distribution in an oil-bearing layer differing with that in a water layer when mud filtrate invasion happens is a common phenomenon. If the array resistivity $\log$ could be applied to the inversion of the actual formation invasion profile, then the fluid property in the reservoir can be recognized more easily.

According to the resistivity distribution characteristics of a fresh mud-invaded oil-bearing layer, the approximate resistivity distribution model around the borehole is established with assumptions that $r_{1}$ is the radius of the flushed zone, $R_{\text {хо }}$ is the corresponding resistivity, the transition zone is between $r_{1}$ and $r_{2}, R_{\mathrm{i}}$ is its resistivity, and the original formation resistivity is $R_{\mathrm{t}}$. Assume that the resistivity in the transition zone has a parabolic distribution, that is, $R_{\mathrm{i}}=a r^{2}+b r+c$, where $r$ is the radial depth, $a, b$ and 

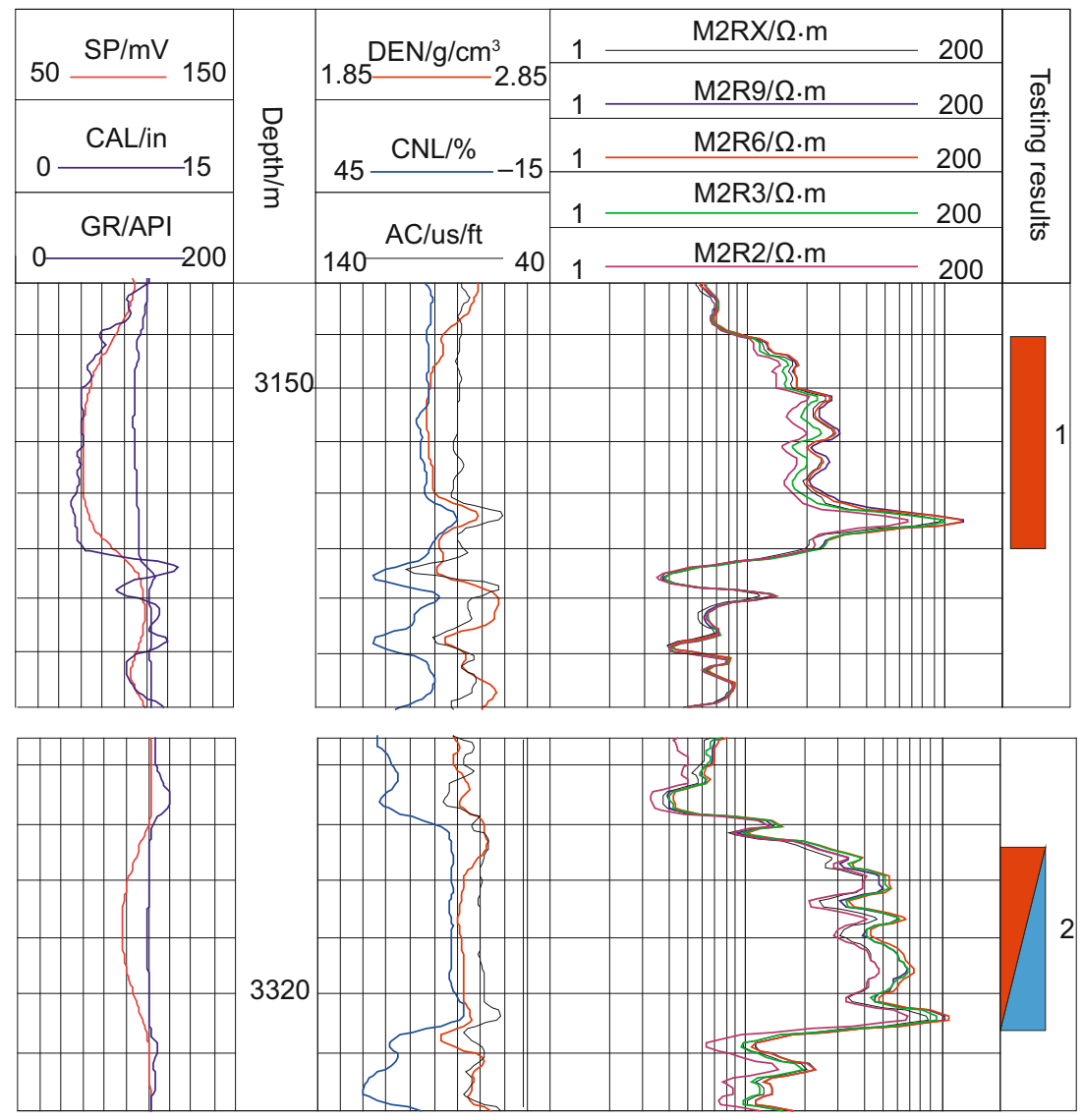

Fig. 3 Comprehensive logging curves of well X

$c$ are coefficients and are determined by $\left(r_{1}, R_{\mathrm{xo}}\right),\left(r_{2}, R_{\mathrm{t}}\right)$ and $\left(0.5 r_{1}+0.5 r_{2}, R_{0.5}\right)$ respectively, where $R_{0.5}$ represents the resistivity of the middle point in the transition zone. Formation parameters $\left(r_{1}, r_{2}, R_{\mathrm{xo}}, R_{\mathrm{t}}, R_{0.5}\right)$ reflect the properties of mud filtrate invasion, and determine the response of the array laterolog in mud-invaded formations.

\subsection{Inversion theory of the array resistivity log}

Formation parameters $\left(r_{1}, r_{2}, R_{\mathrm{xo}}, R_{\mathrm{t}}, R_{0.5}\right)$ determine the response of the array laterolog in mud-invaded formation, represented by the following mathematical function:

$$
y_{i}=f_{i}(\boldsymbol{x}) \quad i=1, \ldots, n
$$

where $\boldsymbol{x}=\left(x_{1}, x_{2}, x_{3}, x_{4}, x_{5}\right)$ is formation parameter vector composed of flushed zone radius, transition zone radius, flushed zone resistivity, transition zone resistivity and original formation resistivity, and $y_{i}$ is the response of the $i^{\text {th }}$ point of the array laterolog. Using the array laterolog to invert the formation parameter $\boldsymbol{x}$ can be converted to an optimized least square problem:

$$
O=\sum_{i=1}^{n}\left(y_{i}-f_{i}(\boldsymbol{x})\right)^{2}
$$

The least square problem in Eq. (6) is transformed into:

$$
\frac{\partial O}{\partial x}=0
$$

The Marquardt method is used to solve Eq. (7) (Zhang, 1984).

\subsection{Field example}

Example 1: Based on the array induction logging data of well $\mathrm{Y}$ in an oilfield in Western China, as shown in Fig. 4(a), the proposed five-parameter inversion method is used for field data inversion, and the processing results are shown in Figs. 4(b) and 4(c). We find that the No.2 layer has a low resistivity annulus from the inverted mud filtrate invasion profile and the original formation resistivity is obviously bigger than the measured logging data, indicating an oilbearing layer. The No.4 layer still has a resistive invasion characteristic, indicating a typical water layer. From the oil testing conclusions, No.2 layer is demonstrated to be an oilbearing layer while No.4 layer is demonstrated to be a water layer, confirming the inversion results.

Example 2: Fig. 5(I) shows the array laterolog curves of well $\mathrm{Z}$ in an oilfield in Western China. In this well No.1 layer, the relatively low resistivity and resistive invasion characteristics indicate a water layer. For No.2 layer and No.3 layer the resistivity increase index is 2 to 3 times the 

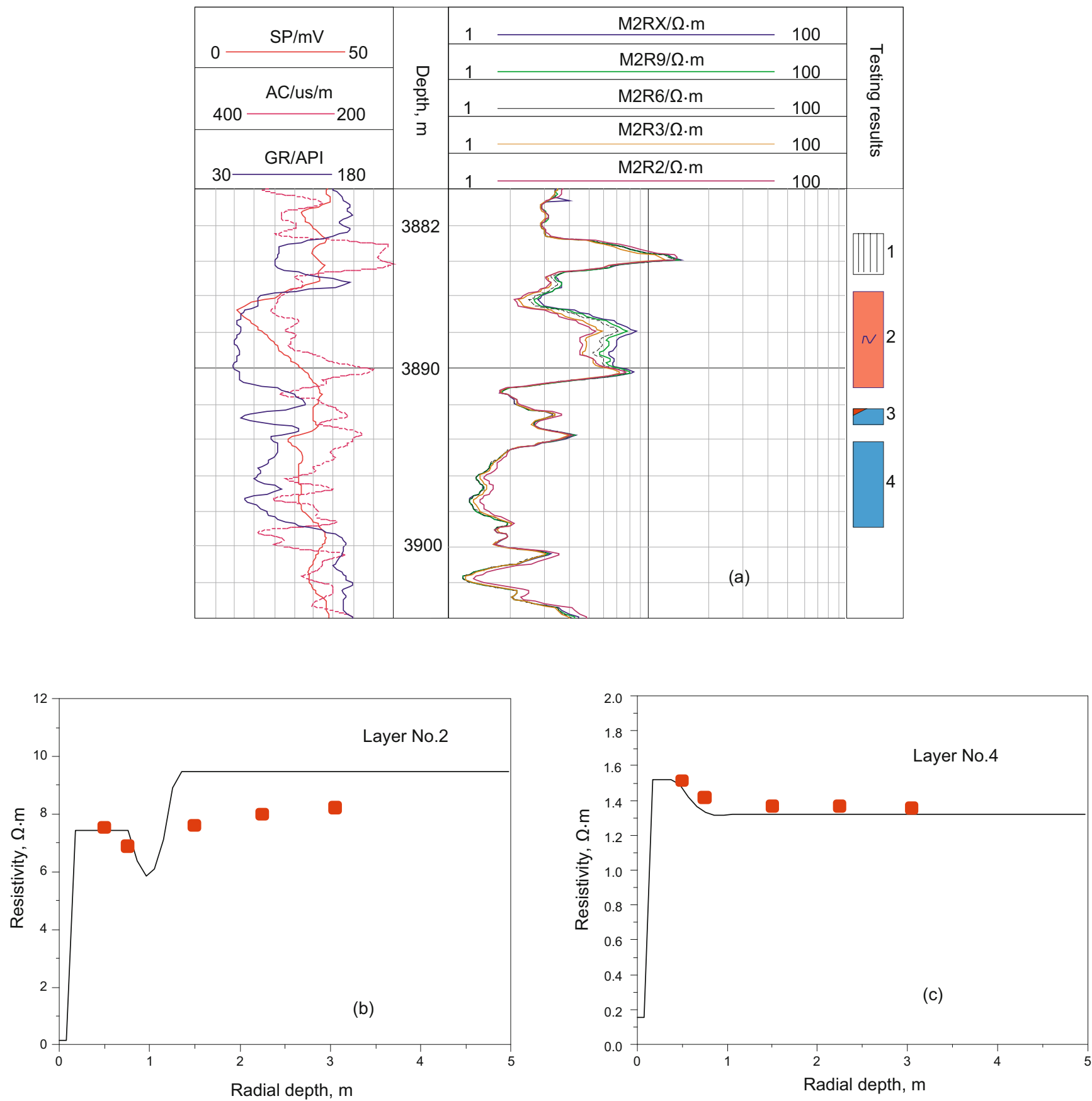

Fig. 4 Array induction logging curves and the corresponding inversion results for well Y. (a) Logging curves. (b) Inversion for No.2 layer. The blue curve represents the inversion result and the red points represent the logging data of HDIL. (c) Inversion for No.4 layer. The blue curve represents the inversion result and the red points represent the logging data of HDIL.

resistivity value of the lower wall rock, indicating an oilbearing layer. The obvious negative difference between deep and shallow resistivity, however, indicates a water layer. Through inversion, the invasion profiles of No.2 layer and No.3 layer, as shown in Fig. 5(II), demonstrate that both the layers show a low resistivity annulus and the resistivity in the flushed zone is higher than that in the original formation. The inversion results support an interpretation of oil-water layers for the two layers. For No.1 layer, the inversion results present a typical water layer with resistive invasion. These are also confirmed through oil testing conclusions. In Fig. 5(II), the square symbols represent the measured array laterolog data, the circle symbols represent the simulation logging responses, and the curves represent the inverted formation invasion profile. 


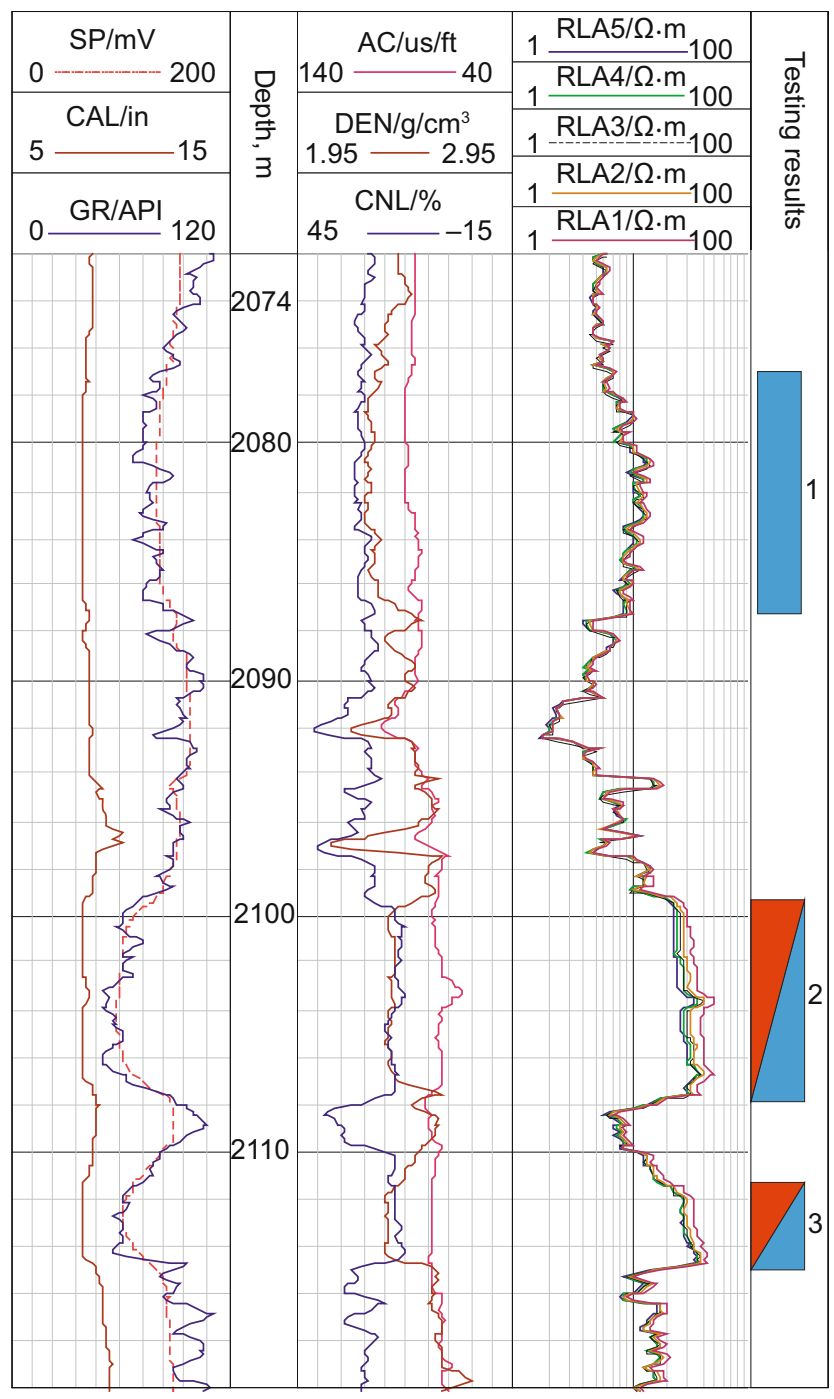

(I) Logs of HRLA of well Z

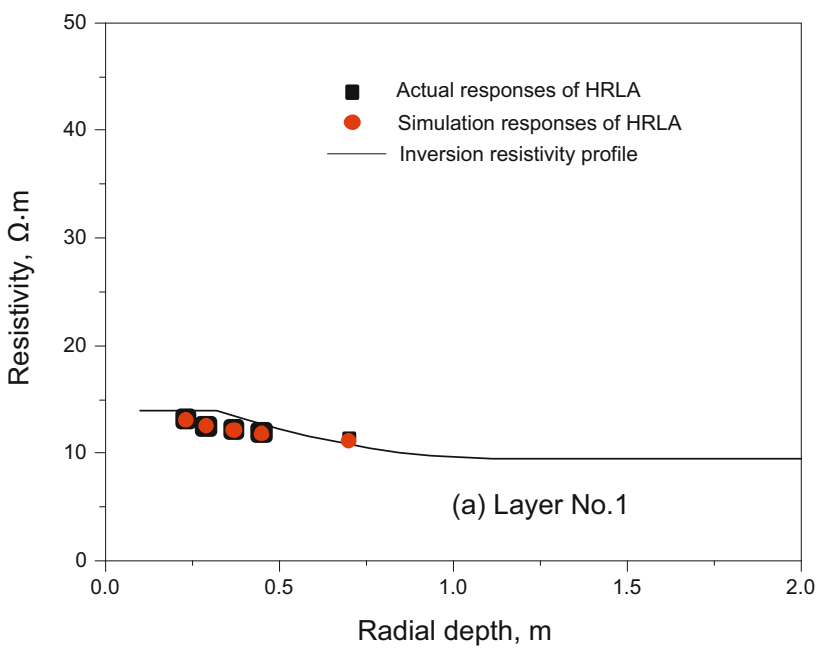

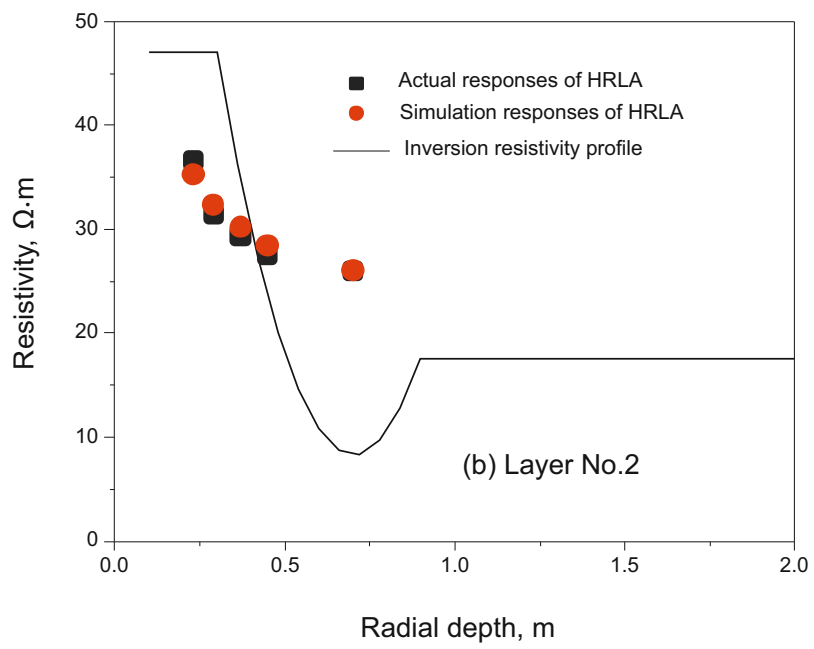

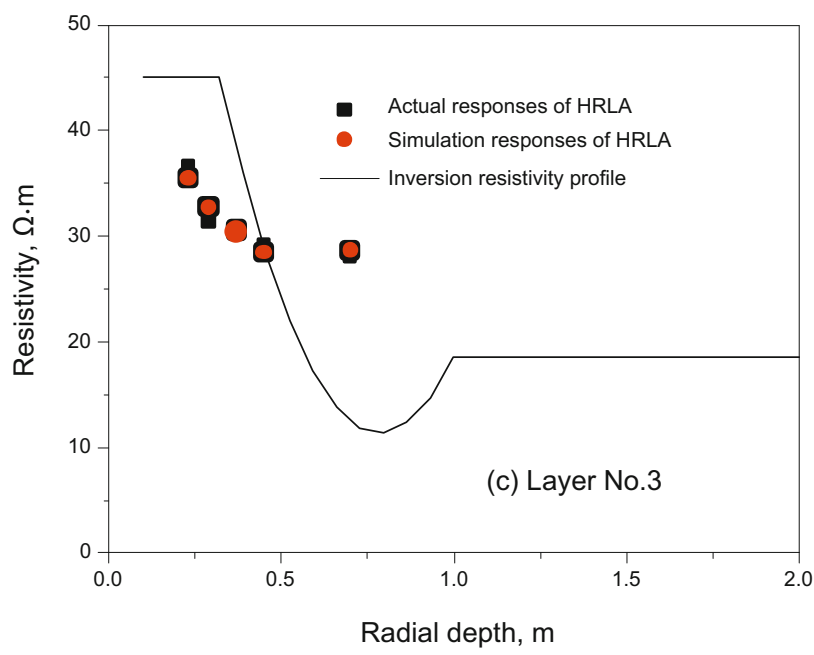

(II) The inversion results

Fig. 5 The array laterolog curves of well Z and the corresponding inversion results

\section{Conclusions}

An oil-bearing layer has a more complex resistivity distribution than a water layer. Monotonic increase, high resistivity annulus and low resistivity annulus are the possible characteristics of a mud-invaded oil-bearing layer.

The deep and shallow array resistivity log commonly deviates greatly from the actual formation invasion profile, resulting in difficulty of identifying fluids with a resistivity log.

The proposed five-parameter inversion method with an array resistivity log can approximately determine the mud filtrate invasion profile. So this is helpful to recognize reservoir fluid based on the difference of invasion properties between an oil-bearing layer and a water layer.

However, the inversion results are open to doubt when the invasion depth is too large and exceeds the investigation depth of the array resistivity log. 


\section{Acknowledgements}

This study is funded by the National Natural Science Foundation (41174009) and National Major Science \& Technology Projects (2011ZX05020, 2011ZX05035, 2011ZX05003, 2011ZX05007).

\section{References}

Barber T D and Rosthal R A. Using a multiarray induction tool to achieve high-resolution logs with minimum environmental effects. SPE Annual Technical Conference and Exhibition, 6-9 October 1991, Dallas, Texas. 637-651

Chen Y H, Chew W C and Zhang G J. A novel array laterolog method. The Log Analyst. 1998. 39(5): 23-32

Chew W C and Liu Q H. Inversion of induction tool measurements using the distorted Born iterative method and CG-FFHT. IEEE Trans, Geoscience and Remote Sensing. 1994. 32: 878-884

Deng S G, Li Z Q, Fan Y R, et al. Numerical simulation of mud invasion and its array laterolog response in deviated wells. Chinese Journal of Geophysics. 2010. 53(4): 994-1000 (in Chinese)

Dewan J T and Chenvert M E. Mud-cake build-up and invasion in low permeability formations: application to permeability determination by measurement while drilling. SPWLA $34^{\text {th }}$ Annual Logging Symposium. 13-16 June, 1993

Gao J, Zhao A B, Peng F, et al. Inversion of array induction logs and its application. Petroleum Science. 2007. 4(3): 31-35

Griffiths R, Smits J W, Faivre O, et al. Better saturation from new array laterolog. SPWLA $40^{\text {th }}$ Annual Logging Symposium. 30 May - 3 June, 1999. 1-13

Li C X, Ouyang J, Zhou C C, et al. Forming mechanism and application of low resistivity annuli in oil reservoirs invaded by fresh drilling mud. Petroleum Exploration and Development. 2005. 32(6): 82-86 (in Chinese)

Liu Z H and Zhang X. Multi-parameter inversion of array laterolog responses. Journal of Xi'an Shiyou University (Natural Science Edition). 2005. 20(1): 30-33 (in Chinese)

Smits J W, Dubourg I, Luling M G, et al. Improved resistivity interpretation utilizing a new array laterolog tool and associated inversion processing. SPE Annual Technical Conference and Exhibition, 27-30 September 1998, New Orleans, Louisiana. 831843

Strickland R W, Merchant G A, Beste R T, et al. High resolution array induction tool. US Patent 6606565. 2003

Wu J, Xie W W, Xie X C, et al. Forward response analysis of an array lateral logging tool. Journal of Xi'an Shiyou University (Natural Science Edition). 2008. 23(1): 73-76, 80 (in Chinese)

Yang $\mathrm{F}$ and Nie Z P. A new inversion method for the formation conductivity profile based on the multi information of array. Acta Electronica Sinica. 2000. 28(6): 135-137 (in Chinese)

Yang $\mathrm{W}$ and $\mathrm{Wu} \mathrm{H} \mathrm{S}$. A dual induction log inversion and its application in Yinggehai Basin. China Offshore Oil and Gas. 2005. 17(1): 21-24 (in Chinese)

Zhang G J. Electrical Logging. Beijing: Petroleum Industry Press. 1984. 31-56 (in Chinese)

(Edited by Hao Jie) 